Mundo Revista de agrario
Mundo Agrario, agosto 2018, vol. 19, n 41, e085. ISSN 1515-5994

Universidad Nacional de La Plata

Facultad de Humanidades y Ciencias de la Educación

Centro de Historia Argentina y Americana

\title{
Memorias chacareras sobre el peronismo histórico en el sur de la provincia de Santa Fe
}

\author{
Evangelina Tifni \\ Consejo Nacional de Investigaciones Científicas y Técnicas, \\ Instituto de Investigaciones en Ciencias Agrarias de Rosario (IICAR), \\ Grupo de Estudios Agrarios (GEA), Argentina \\ tifnievangelina@gmail.com
}

Cita sugerida: Tifni, E. (2018). Memorias chacareras sobre el peronismo histórico en el sur de la provincia de Santa Fé. Mundo Agrario, 19(41), e085. https://doi.org/10.24215/15155994e085

Recibido: 20 de Noviembre 2017 - Aceptado: 10 de Abril 2018 - Publicado: 15 de Agosto 2018

(c) (1) (2) Esta obra está bajo licencia Creative Commons Atribución-NoComercial-CompartirIgual 4.0 Internacional

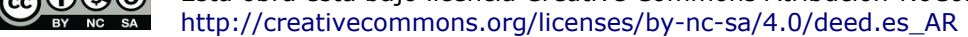




\section{Memorias chacareras sobre el peronismo histórico en el sur de la provincia de Santa Fe}

Chacareras memories about the historical Peronism in the south of the province of Santa Fe

Evangelina Tifni

Consejo Nacional de Investigaciones Científicas y Técnicas,

Instituto de Investigaciones en Ciencias Agrarias de Rosario (IICAR),

Grupo de Estudios Agrarios (GEA), Argentina

tifnievangelina@gmail.com

\section{Resumen:}

El objetivo de este artículo es presentar las representaciones de los productores del sur de la provincia de Santa Fe en torno a la política agraria implementada durante los dos primeros gobiernos de Perón (1946-1955) En este período fueron muchas las medidas implementadas para el desarrollo del agro pampeano. Optamos por un diseño metodológico netamente cualitativo basado en entrevistas en profundidad y análisis de fuentes documentales emitidas por las cooperativas agrarias durante el periodo en estudio. Así, vemos como los productores (re)construyen la historia, su historia, a partir de la narración de hechos cotidianos.

Palabras clave: Santa Fé, Chacareros, Política agraria, Peronismo, Memoria.

\section{Abstract:}

The objective of this article is to present the farmer's representations installed in the south Santa Fe province about agrarian politic during the two first Perón government (1945-1955) During this period, a lot of deciding adopted development agriculture pampeano. We choose methodological qualitative model based on detailed interviews and we analyzed the authorize documents by the agrarian cooperative society during the time we studied. We can see how the farmers rebuilt the history, their history, since the stories daily acts narrative.

KEYWORDS: Santa Fé, Memory, Farmers, Peronismo, Agrarian political.

\section{INTRODUCCIÓN}

Muchas fueron las políticas implementadas por el gobierno de Juan Domingo Perón (1946-55) para incentivar la producción agropecuaria de los pequeños y medianos productores pampeanos y a sus cooperativas; muchos fueron los conflictos sucedidos en este período entre distintos actores sociales presentes en el espacio social -entre productores y trabajadores, entre productores y acopiadores, entre productores y el gobierno-; muchos fueron los chacareros arrendatarios que pudieron acceder a la propiedad de la tierra, cumpliéndose de este modo una vieja bandera de la Federación Agraria Argentina (FAA) y que en un discurso pronunciado el 01 de enero de 1946 en el marco de la campaña electoral en la ciudad de Santa Fe, Perón retoma y hace propia: "la tierra a quien la trabaja".

Además, se regularon las condiciones laborales de los trabajadores rurales - tanto transitorios como permanentes- a partir de la implementación de diferentes estatutos como el del Tambero-mediero, el del Peón Rural y el fortalecimiento de los Centros de Oficios Varios y la posterior creación de la Federación de Trabajadores Rurales y Estibadores. Paralelamente, se produjo la mayor institucionalización del movimiento cooperativo agrario argentino y -en particular a partir del Segundo Plan Quinquenal- se promovió su expansión, siendo este uno de los ejes centrales de dicho plan.

En este marco, las cooperativas agrarias en el sur de la provincia de Santa Fe surgieron como una estrategia colectiva para revertir una situación histórica previa de debilidad de los pequeños y medianos productores rurales. Frente a la desventaja en la comercialización individual, estas instituciones se constituyeron como un factor de empoderamiento de los chacareros que -al eliminar la intermediación del privado- eran ellos mismos quienes directamente vendían su producción. Es decir, las cooperativas se constituyeron en un mecanismo social que les posibilitó disminuir los riesgos que tenían como productores individuales. 
Si bien las primeras experiencias cooperativas en nuestro país surgieron hacia fines del siglo XIX, podemos marcar como momento de auge del cooperativismo agrario pampeano al período que abarca entre 1922 y 1956. Tal como lo muestra el cuadro No 1, la provincia de Santa Fe tuvo un rol protagónico en el desarrollo del movimiento a nivel nacional.

Estas instituciones fueron actores clave en el desarrollo de las localidades agrarias de esta región. Se localizaron en los cascos urbanos y se convirtieron en el nexo entre dos mundos aparentemente contrapuestos; sin embargo, para el desarrollo del agro, se complementan.

Cuadro $N^{\circ} 1$ : Evolución de las cooperativas, provincia de Santa Fe. 1940/47

\begin{tabular}{|c|r|r|r|r|}
\hline Año & $\begin{array}{c}\text { Capital } \\
\text { realizado } \\
\mathbf{\$ m} / \mathbf{n}\end{array}$ & $\begin{array}{c}\text { Capital suscripto } \\
\mathbf{\$ m} / \mathbf{n}\end{array}$ & $\begin{array}{c}\text { Operaciones } \\
\mathbf{\$ m} / \mathbf{n}\end{array}$ & Número de socios \\
\hline $1940 / 41$ & 5.129 .799 & 7.409 .520 & 48.712 .404 & 67.737 \\
\hline $1941 / 42$ & 6.117 .017 & 8.709 .358 & 67.048 .154 & 73.022 \\
\hline $1942 / 43$ & 7.588 .516 & 10.186 .284 & 96.013 .401 & 76.694 \\
\hline $1943 / 44$ & 8.788 .502 & 13.370 .048 & 193.849 .465 & 80.753 \\
\hline $1944 / 45$ & 10.683 .702 & 14.854 .746 & 207.752 .956 & 85.085 \\
\hline $1945 / 46$ & 12.850 .990 & 16.380 .762 & 122.968 .952 & 88.521 \\
\hline $1946 / 47$ & 16.669 .756 & 21.305 .895 & 199.450 .397 & 97.723 \\
\hline
\end{tabular}

Fuente: Tumini, 2013.

En este artículo, nos interesa (re)presentar la historia del sur de la provincia de Santa Fe desde la voz de los pequeños y medianos productores agropecuarios vinculados con las cooperativas agrarias de comercialización; nos interesa conocer cómo recuerdan la etapa del peronismo histórico, cómo ese pasado es vivido y significado en la actualidad, cómo la memoria de un grupo social se (re)construye a partir del relato, del recuerdo de una etapa histórica.

Existen muchas investigaciones sobre las cooperativas agrarias durante dicho período. Algunas lo hacen, desde análisis institucionales ${ }^{1}$, otras analizan las políticas públicas ${ }^{2}$ y su impacto en el espacio social. Por otra parte, se han realizado diversos estudios ${ }^{3}$ a partir del análisis de los relatos de los actores -entre otros temas- sobre la relación entre el peronismo y el movimiento obrero, la consolidación de los sindicatos, la construcción de la identidad peronista siempre circunscripto al mundo urbano. No hallamos trabajos donde se recuperen relatos orales de productores sobre las cooperativas agrarias en el peronismo.

Este artículo es una síntesis de la tesis doctoral "Memorias del mundo chacarero en torno a la expansión del cooperativismo agrario pampeano en la provincia de Santa Fe. 1946/1955”, desarrollada en el marco del Programa de Doctorado en Ciencias Sociales de la UBA.

\section{CONSIDERACIONES TEÓRICO-METODOLÓGICAS}

Realizamos el abordaje de nuestra problemática a partir de marcos conceptuales provenientes de diversas disciplinas: Sociología, Ciencia Política e Historia. Esto implicó un diseño netamente cualitativo ya que partimos de una concepción teórica que busca lo social sumergido en lo más profundo de lo particular.

Construimos la fuente de información primaria a partir de la realización de veinticuatro entrevistas narrativas con aportes de los relatos de vida (Sautu, Boniolo, Dalle y Elbert 2005; Bertaux, 2005) a 
productores socios fundadores, productores socios actuales, familiares directos, actuales gerentes y exgerentes de las cooperativas de comercialización agropecuarias de seis localidades del sur de la provincia de Santa Fe que se fundaron bajo el gobierno peronista ${ }^{4}$, e historiadores de seis localidades del sur santafesino. Para su realización aplicamos una guía evolutiva (Bertaux, 2005) en la que planteábamos ejes generales; por tanto el gobierno peronista (1946-1955) y las políticas implementadas iban siendo mencionadas por los entrevistados. Las categorías en las cuales se ubican las memorias de los entrevistados en torno a este tema son el resultado del análisis realizado. Sabiendo que el contenido de los discursos no puede aislarse de su contexto de producción y condiciones de enunciación, optamos por el análisis comprensivo.

Complementariamente, analizamos la información de fuentes documentales emitidas por las cooperativas en el período correspondiente: balances, actas de las asambleas, actas de las reuniones del Consejo de Administración, revistas aniversario, periódico La Tierra ${ }^{5}$, publicación de FAA. Siguiendo los recaudos metodológicos propuestos por Portelli $(2003,2004)$, estas fuentes fueron analizadas luego de haber realizado las entrevistas como forma de obtener información complementaria y no para corroborar la veracidad de lo dicho por los entrevistados.

\section{CARACTERIZACIÓN DE LOS SOCIOS FUNDADORES Y PRIMEROS ASOCIADOS}

Los asociados formaban parte del universo de productores que podemos caracterizar como integrantes del "mundo chacarero": organizaban su unidad de producción involucrando el trabajo de toda la familia. Es decir, se trata de una forma de producción que sin las características que le otorga la base familiar no podría persistir. Todos los entrevistados señalan esta condición en sus chacras, en el caso de los más jóvenes hablan del padre o abuelo con sus hijos y nietos (entrevistados $N^{\circ} 2,4,5,9,12,15,17,18,19$ ) y en el caso de los productores más viejos eran ellos con sus esposas e hijos (entrevistados $\mathrm{N}^{\circ}$ 1, 3, 10, 13, 16) No se trataba sólo de familias nucleares sino que -en algunos casos- eran familias ampliadas y se incorporaban personas que, sin lazos de parentesco, pertenecían a las mismas zonas de Europa de donde eran ellos ya que en su gran mayoría se trataba de inmigrantes $-o$ descendientes de inmigrantes- europeos.

\footnotetext{
En la casa no es que vivían ellos. Vivían ellos, los hermanos, por ejemplo en la casa de campo de mi papá, vivían los tres hermanos de mi abuelo y mi papá se crío con todos los primos (Entrevistado No 15)

En casa vivíamos el abuelo con sus dos hijos, las nueras y un nieto que era yo. Además una mucama y a veces algunos peones (Entrevistado No 2)
}

Estos productores pertenecían a una misma zona, es decir, se conocían, eran amigos, vecinos, familiares.

\footnotetext{
Se juntaron primero 6 ó 7 amigos, productores todos, se juntaron entre ellos y hablaron de la posibilidad de venir a acá a Rosario a una reunión para saber qué tenían que hacer porque... era un hecho que funcionaban mejor si entre ellos se juntaban y... lo hicieron (Entrevistada No 5)
}

El total de los productores entrevistados producían en la chacra mixta: unidad en la que se articula la agricultura y ganadería, tanto para la comercialización como para el autoconsumo. Dentro de las producciones domésticas, en todas las casas había pollos, huevos, vacas y tenían la desnatadora que hacían la crema, después la manteca (Entrevistado No 2), huerta, frutales, algún cerdo para faena. Las carneadas y las yerras eran momento de encuentro y diversión entre las familias productoras ya que se invitaba a participar a vecinos, parientes, amigos; solían durar varios días.

Nos habían dado 2 ha para que tengamos vaquitas para ordeñar y tener la leche fresca todas las mañanas (...) mi mamá nos hacía la ropa porque en aquel tiempo se hacía la ropa para los chicos (Entrevistado $\mathrm{N}^{\circ} 12$ )

No había un peso. Nosotros vivíamos a gallina, pollo, huevos y pará de contar y la carne una vez por semana, una vez cada tres o cuatro días que pasaba el carnicero, el repartidor, nos dejaba la carne y a fin de mes se le pagaba, teníamos una libreta (Entrevistado No 10$)$ 
Esta articulación entre unidad productiva y doméstica se diluye con el avance de la agriculturización. La mayor parte de nuestros entrevistados mencionan haber abandonado la actividad ganadera cuando llegó la soja y la imposibilidad de retomarla dado que las generaciones más jóvenes no están capacitadas o interesadas en ello. Así, reflejando estas transformaciones ocurridas al interior de las chacras, muchas de las cooperativas comenzaron siendo agrícolas ganaderas para luego especializarse en la comercialización de cereales y oleaginosas.

\section{REPRESENTACIONES EN TORNO AL PERONISMO}

Las representaciones son imágenes que construimos a partir de una vivencia experimentada por nosotros o por otros. Así, palabras, colores, aromas, sentimientos se articulan para construir esa representación sobre un hecho, una cosa, una persona, un momento y otorgar también un significado. Esas representaciones están permeadas por el tamiz del tiempo, por nuevas vivencias, por nuestras transformaciones. Es decir, las representaciones sociales no son simplemente una forma de entender la realidad social sino que implica un proceso de construcción de la misma. En este punto, se articula con la noción de habitus planteada por Pierre Bourdieu $^{6}$. A continuación presentamos las representaciones en torno a la política laboral (Estatuto del Peón ${ }^{7}$, Sistema de turnos rotativos, Conflictividad con los trabajadores temporarios), la Política económica orientada al agro (representaciones en torno al IAPI y sobre el accionar del Banco Nación) y política de tierras.

\section{Política laboral}

Los dos primeros gobiernos de Perón se caracterizaron por una ampliación en los derechos laborales, lo que incluía tanto a trabajadores urbanos como rurales. Los chacareros cifran particularmente sus críticas al peronismo desde esta legislación, inclusive hoy en día es objeto de denostaciones a toda la política del período. Entre los años 1944 y 1947 se establecieron una serie de disposiciones legales tendiente a regular la situación laboral en el sector rural. Entre ellas podemos señalar el Estatuto del Tambero-Mediero de 1946, que medió las relaciones entre los dueños de los tambos y los productores encargados del trabajo (medieros) y el fortalecimiento de los Centros de Oficios Varios, en los que los obreros transitorios se sindicalizaron y eran los administradores de la mano de obra por medio del control de las bolsas de trabajo.

\section{Estatuto del Peón}

El 17 de octubre de 1944, por Decreto-Ley № 28.169, se instauró el Estatuto del Peón que estableció las condiciones de trabajo que rigieron para todos los asalariados rurales mensuales o permanentes: retribución por zonas estableciendo un salario mínimo -que casi duplicaba a los existentes- y las normas de desenvolvimiento higiénico, alojamiento, alimentación, descanso, reglas disciplinarias, vacaciones pagas, indemnización por despido sin causa justificada, ahorro voluntario y asistencia médica y farmacéutica a cargo del empleador. El mismo no se aplicaba para trabajadores temporarios o de cosecha que se sindicalizaban en los Centros de Oficios Varios que regulaban las bolsas de trabajo.

Según el entonces Coronel Perón, con este Estatuto se tendía a solucionar uno de los mayores problemas de la política social del país, ya que muchos de los peones de campo se encontraban en condiciones de cuasi esclavitud. Según Lattuada (1986), sin una lucha organizada previa, los trabajadores rurales permanentes consiguieron condiciones sociales y económicas sin antecedentes.

Los entrevistados distinguen entre aquellos trabajadores permanentes que convivían con las familias o trabajaban habitualmente, sobre los que había un conocimiento y una relación cotidiana, y aquellos 
trabajadores transitorios que ocasionalmente trabajaban en las chacras. Estos últimos fueron los que más confrontaron con los productores.

\section{¿Cómo estaba organizado el trabajo?}

Y...nosotros éramos toda la familia, papá y nosotros tres y teníamos un mensual. Entonces en tiempo de cosecha no lo dejaban trabajar al mensual.

¿El mensual vivía con ustedes?

$\mathrm{Si}$, vivía con nosotros. Pero, ya ahí no lo dejaban trabajar porque este... no entraba en el turno. O sea, que vos tenías que ir al sindicato y decías: necesito 3 asadores, necesito 1 costurero. No podías coser vos, por ejemplo, en la máquina alguno de nosotros no podía ir. Todas esas cosas, bueno, eso generaba bastante tensiones. Pero eso duró hasta que duró el peronismo. O sea que se empezó a dividir el trabajo entre todos. Que antes por ahí había más desocupados porque cada productor tenía su personal, viste (Entrevistado No 1 )

Esta medida fue celebrada por el sector beneficiario pero altamente resistida por los sectores productores, incluidos tanto los pequeños y medianos propietarios y arrendatarios como los grandes productores, en su mayoría representados por la Sociedad Rural Argentina ${ }^{8}$. Al establecer el aumento salarial, entre otras exigencias, en un tiempo de crisis, los arrendatarios intensificaron el uso de mano de obra familiar y aumentó la desocupación. Este sector consideraba que dicho Estatuto iba en contra de los “intereses morales, técnicos y económicos de quienes trabajaban y servían al campo (La Tierra, 29 de diciembre de 1944) Tal es así que "reunido el Consejo Directivo de Federación Agraria Argentina resolvió dirigirse al Presidente de la Nación pidiéndole la derogación o reforma substancial del Estatuto del Peón” (La Tierra, 03 de noviembre de 1944)

En el momento de su implementación, la posición de la FAA y de los productores por ella representados fue contraria a este Estatuto y realizaron activas acciones de protesta. Esta medida no fue problematizada por nuestros entrevistados como un momento de conflicto. En sus representaciones, la política laboral peronista de fortalecimiento de los sindicatos rurales es lo primero que aparece como conflictiva y que atentaba directamente contra sus intereses. No así el Estatuto del Peón. Una explicación posible es que estos productores no tenían a su cargo muchos asalariados permanentes y sí debían recurrir frecuentemente a la contratación de temporarios.

El establecimiento del Estatuto del Peón fue posible, en primer lugar, porque Perón -a través de su discurso y también desde lo práctico- resignificó el concepto de lo social, de la cuestión social. Antes de su llegada a la Secretaría de Trabajo y Previsión Social, la cuestión social era considerada como ajena a la arena política, como problemáticas propias de los inmigrantes en las cuales debía intervenir la policía y de las que debían ocuparse las damas de caridad, entre otros. Con Perón esto cambia. Lo social se convirtió no sólo en tema político, sino que se inició la "era de la política social", como una obligación del Estado para con sus ciudadanos. De esta forma, comenzó a delinearse un nuevo sujeto: el sujeto "clase obrera organizada", "clase trabajadora", para luego convertirse en el sujeto "Pueblo-Trabajador", un protagonista indiscutido, no sólo del discurso de Perón, sino de todo el período peronista (Svampa, 2006; Sigal y Verón, 1982)

Esto implicó una ruptura con las formas anteriores; cambió la forma de intervención del Estado en los conflictos sociales. La legislación social de la época significó el reconocimiento por parte del Estado de muchos de los derechos por los que estaba peleando el movimiento obrero organizado. Esta nueva forma de relación entre el Estado y los trabajadores formó parte de la estrategia que Perón desarrolló para frenar el avance comunista. Así, se relacionó con un movimiento obrero y su cúpula sindical (dejando por fuera de esto a los comunistas), formada durante la restauración conservadora y sus prácticas represivas que veían en esta legislación una esperanza de cambio (Svampa, 2006; Torre, 2002; Guilani, 2008)

Perón, en su discurso, colocó al Estatuto del Peón en un lugar imprescindible, a partir del cual se solucionaba, según su criterio, uno de los mayores problemas de la política social del momento: las condiciones de vida de los trabajadores rurales. Como dijimos recién, este tratamiento político de la cuestión social no hubiese sido posible sin la previa redefinición de la misma. Según Perón, "la Constitución del 53 
abolió la esclavitud, pero lo hizo teóricamente, porque no es menor la esclavitud de un hombre que en el año 44 trabaja para ganar 12, 15 ó 30 pesos por mes."(Lattuada, 1986, p. 41)

\section{Sistema de turnos rotativos}

Los trabajadores temporarios se agrupaban en los Centro de Oficios Varios. Su momento de auge fue mientras Perón se encontraba en funciones en la Secretaría de Trabajo. Estos Centros controlaban las bolsas de trabajo. Los trabajadores permanentes (peones o mensuales) no podían sindicalizarse en este espacio. Entre sus funciones principales fijaron la escala de jornales y especializaciones asignando tareas técnicas que nunca habían tenido jerarquización alguna, así se institucionalizaron especializaciones como la de "pistín" y los "alzadores de bolsas". De esta forma, gracias al apoyo brindado por la Secretaría de Trabajo y especialmente por Perón, obtuvieron "el poder de establecer y aún de imponer las condiciones de trabajo y jornales. Un poder que jamás habían conocido, ni logrado por sus propias luchas, y que sólo había sido patrimonio de los sectores patronales" (Lattuada, 1986, p. 53)

Además, organizaban el sistema de turnos de trabajo o turnos rotativos con el objetivo de paliar la desocupación: cada trabajador era ocupado menos tiempo asegurándose así un ingreso mínimo para su subsistencia. El sistema de jurisdicciones de trabajo o jurisdicciones cerradas establecía que un alto porcentaje (en un primer momento fue el $60 \%$ y posteriormente se pasó al 70\%) de los obreros contratados debía estar afiliado al sindicato y ser de la zona de la producción. Este sistema, sumado a otras causas (industrialización, desarrollo de las economías regionales y crisis de la agricultura pampeana), contribuyó a la disminución de las migraciones golondrinas internas.

El mismo fue calificado por el periódico La Tierra (07 de noviembre de 1954) como "injusto, peligroso y antipatriótico",como algo que no contribuía a reducir los índices de desocupación entre los trabajadores rurales y obstaculizaba el progreso técnico y social del agro.

Nosotros teníamos el campo en la zona de Gral. Roca ${ }^{9}$ y teníamos que poner gente del sindicato de allá. Nosotros teníamos
los amigos, conocido acá en Tortugas (...) y había que sacarlos. El obrero de Tortugas no le pertenece acá, decía. Y tenías que
cargarlo, traerlo, pagarle lo que había hecho... pero te mandaban algunos que no sabía quiénes eran, cómo vas a tener en tu
casa gente que no sabes quién son (Entrevistado No 13 ) El capataz del sindicato me mandaba a esa gente y yo no podía seguir
trabajando con esa gente porque... no se podía. Entonces yo digo, yo quiero elegir la gente, yo pongo gente de acá y de Gral.
Roca, pero yo la elijo. Y así fue, se armó una cuadrilla, me parece que eran cinco, tenía un mensual que sabía cómo se trataba
un caballo, los otros no sabían los caballos, no sabían petizar, no sabían nada. Entonces le dije que yo quería así, bueno, me
aceptó. Y esa cuadrilla la tuve mucho tiempo, como 11 años. Y después bueno, ya vino la otra, como se llama... la cosechadora
grandota que ya no se embolsaba más entonces los negros ya... (Entrevistado No 10$)$

En general, los entrevistados sostienen que antes del peronismo "todos los años en tiempo de cosecha cada productor tenía dos o tres trabajadores que eran de la familia. Con los turnos esto se terminó (Entrevistado No 1$)$ ”

Los productores recurrían a diversas estrategias para poder sortear estas disposiciones. Muchos especulaban o esperaban los turnos de los trabajadores que conocían. Así, esta práctica acentuó la diferencia entre productores y trabajadores; para los chacareros, esta situación antes podía salvarse a partir del conocimiento cara a cara característico de estas sociedades pequeñas. La idea de comunidad se circunscribía sólo a quienes se consideraba pares, con los que se compartía la posición en el campo.

Con la promulgación de la Ley 13.020 en el año 1947, estos Centros perdieron poder, ya que dicha ley garantizó a los arrendatarios el derecho a usar el trabajo familiar y eliminó el pago del trabajo no realizado. La decadencia total se dio ese mismo año, cuando la CGT estimuló la creación de la Federación Argentina de Trabajadores Rurales y Estibadores (FATRE) Se encontraba totalmente subordinada a la CGT y sus discursos se "confunden" con los discursos gubernamentales. En ellos se incentivaba a la producción, se abogaba a favor de la armonía de clases y se desestimaban las huelgas agrarias bajo la consigna: "En ningún 
caso el desacuerdo puede originar la paralización de las actividades". Esta misma consigna aparece en los documentos emitidos sobre la regulación del trabajo rural formulados por la Comisión Nacional de Trabajo Rural.

Con esto queremos señalar que la práctica de imposición de trabajadores y el pago por trabajo no realizado estuvo vigente aproximadamente tres años de los casi nueve que Perón estuvo en el poder. En este sentido, se torna interesante observar lo que se rescata en la memoria de este grupo como política y se ocultan otros aspectos.

\section{Conflictividad con los trabajadores temporarios}

Otra de las prácticas que llevaron adelante los Centros de Oficio, con acuerdo de la policía y de los jefes políticos locales, era la imposición obligatoria de personal asalariado. La formación de cuadrillas de peones y el uso de mano de obra familiar fueron reglamentados por primera vez con el Decreto No 29.715 en noviembre de 1945. Si bien no era muy claro respecto a la regulación del trabajo familiar y las cuadrillas, dejaba en manos de las Delegaciones Regionales su aplicación. En abril de 1946, se dictó el Decreto No 11.856 que reguló explícitamente el trabajo familiar y la organización de cuadrillas para la cosecha, desgrane y transporte de maíz y girasol.

Esta imposición de trabajadores estaba acompañada del cobro o pago por trabajo no realizado. En la mayoría de los casos, con el apoyo de la policía local se presionaba a los productores para que abonen los jornales a los trabajadores cuando eran reemplazados por sus familiares en el desempeño de las labores. Luego de diversos comunicados del Ministerio de Agricultura sobre esta cuestión, el gobierno nacional en 1947 dictó el Decreto 7.451 que incluyó por primera vez una cláusula que prohibía el pago por trabajo no realizado (Mascali, 1986)

\footnotetext{
Yo lo que tengo... la herencia de los mayores... que no estaba bien visto el peronista por el tema de que eran muy autoritarios. En el campo, por ejemplo, tenían que poner a los empleados del sindicato mientras que los hijos de los dueños del campo no podían trabajar. Bueno, eso... un poco lo que yo supe de chico, comentaba mi padre, mi suegro... la gente que comentaba, que había que afiliarse al partido peronista, en el tiempo de la muerte de Evita había que llevar el luto obligatorio, bueno todas esas cosas (Entrevistado No 9 -60 años)

Yo era chico en esa época, tenía 10 años más o menos. Pero me acuerdo que mi padre no dejaba que se nombre a Perón en mi casa, si fuese por eso, yo no lo quiero. Yo me acuerdo que cuando era época de trabajo venían los del sindicato con la policía, venían y no nos dejaban trabajar; los teníamos que poner a ellos y pagarles (...) nosotros éramos 7 hermanos, sobraba trabajo en el campo y no podíamos trabajar (Entrevistado No $19-76$ años)
}

Los entrevistados más jóvenes, cuando hablan respecto a la época peronista -dado que se trata de un período generalmente anterior a su nacimiento, o en el que eran niños o jóvenes-- recurren a la recuperación de relatos de otros. Construyen su narrativa a partir de experiencias, acontecimientos, pareceres de otros con los que el entrevistado se identifica. Así, se hace presente la memoria heredada (Pollak, 2006) que contribuye a la cohesión del grupo social generando un pasado compartido por ellos y diferente al de otros grupos sociales.

Por su parte, los entrevistados más viejos reviven en primera persona el momento pasado, reconstruyen la historia a partir de sus propias vivencias.

Por ejemplo la costumbre que había en tiempo de cosecha o cuando se trabajaba era que cada productor en el campo tenía, digamos... dos o tres obreros que permanentemente trabajaban en la cosecha, gente que era así como de la familia. Todos los años en tiempo de cosecha venían, comían junto con uno, dormían junto con uno. Eran de la familia. Entonces, bueno, cuando empezaron a tener más poder los sindicatos se formaron los turnos, entonces se turnaban, te traían la gente y te decían bueno: usted tiene que llevar a este, este o este que están ahí. Y eso generaba ciertas tensiones. Pero se siguió trabajando lo mismo (Entrevistado No $1-82$ años)

Los sindicatos mandaban ellos. Venían al campo, nosotros teníamos que hacer los trabajos brutos, después venían ellos, levantaban la cosecha y si no te gustaba: 'Viva Perón!' te denunciaban y venía la policía. Fue bravo eso... esos tiempos eran... 
en el año '50 y antes que cayera Perón eran los sindicatos obreros rurales los que mandaban, mandaban ellos (Entrevistado No $13-81$ años)

Lo interesante de este último fragmento es que quien lo cuenta es un exproductor que se reconoce peronista. Reconoce los avances y las mejoras que obtuvo durante ese período y cómo mejoró su situación durante el gobierno peronista, lo que no quita su comentario en contra del accionar de los sindicatos y la policía.

Estas prácticas fueron durante mucho tiempo denunciadas por la FAA en su periódico La Tierra, con diversos artículos que alentaban a los productores y a sus familias -sobre todo a los hijos varones- a resistirse a ellas y defender la "integridad en las chacras"; llamaban al gobierno a que establezca una certera regulación sobre los salarios rurales y a las autoridades a que "no confundan su función específica de guardianes y consejeros del orden. No se metan en lo que no les importa y está siendo motivo de rebelión en los sectores de la producción afectada por medidas inconsultas y arbitrarias" (La Tierra 14 de mayo de 1946)

Respecto a la imposición de trabajadores asalariados y al pago por trabajo no realizado, en un artículo titulado "La libertad de trabajo debe existir en la chacra", publicado en el recién mencionado periódico, sostenían que se negaban a realizar estas prácticas y solicitaban a sus lectores a hacerlo también. Alegaban que si en otros rubros de la economía como las peluquerías, los almacenes, bares, etc., los dueños no incorporaban trabajadores cuando no los necesitaban, por qué iban a hacerlo ellos. Además, defendían el derecho a usar la mano de obra familiar y de allegados o conocidos suyos. Así, sostenían que si

la cosecha no rindió para nosotros, entonces, ¿por qué debemos dar a otros lo que no tenemos? Hay quienes tienen 1.000 ha de tierra y no dan 100 a quienes carecemos de ellas. Y a ningún gobierno se le ocurrió entregárnosla. ¿Cómo vamos nosotros, que carecemos de dinero, a compartir, porque sí, con los peones, por el derecho de tener estos tanto o menos que nosotros? (...) Los peones tienen derecho de exigir que se les pague lo que les parece oportuno. Pero negamos el derecho a obligarnos a darles trabajo. Les negamos a las autoridades el derecho de presionarnos para que cedamos a semejantes presiones (La Tierra, No 4199, 07 de noviembre de 1954)

Esta medida fue tan resistida porque, entre otras cosas, implicó reducir una de las condiciones más importantes para la flexibilidad de la producción simple de mercancía: la capacidad de recurrir a la propia mano de obra familiar, inclusive a la autoexplotación de la fuerza de trabajo, a fin de evitar tener que disponer en forma permanente de un fondo de salario. Este modelo de asalarización del agro pampeano fue contradictorio con esta forma de producción en la que se recurría a la contratación de asalariados sólo cuando se la consideraba imprescindible. El chacarero basaba su estrategia de permanencia -y acumulación ampliada cuando el contexto lo permitía - a partir de la intensificación del uso de la mano de obra familiar.

\section{Política económica orientada al agro}

\section{Intervencionismo económico. Representaciones en torno al IAPI}

En su totalidad los entrevistados recuerdan al gobierno peronista (1946-1955) como un período de intervencionismo económico "con algunas particularidades que ayudó a los productores" (Entrevistado No2); resaltando las retenciones que realizaba el gobierno al sector agrario a través del IAPI para financiar el desarrollo del sector industrial. En el año 1946 se sancionó la ley No 13.962 que estableció la creación del Instituto Argentino para la Promoción del Intercambio (IAPI), responsable de centralizar la producción de granos.

$¿ V i s t e$ que se discute de las retenciones que hay ahora en el campo? Las retenciones en ese momento eran extraordinarias, uno si hablaba en dólares habrá llegado a haber hasta un cuarenta y pico por ciento de retenciones. El campo fue el que motorizó las industrias. Del campo salieron los fondos para comenzar a industrializar el país en esa época (Entrevistado $\mathrm{N}^{\circ} 2$ ) 
Toda la comercialización de granos pasaba por el gobierno. O sea, que las cooperativas y los acopiadores que había se lo vendían al IAPI. El gobierno era el que se encargaba de venderlo al exterior o a las aceiteras y molinos, o a quien sea (Entrevistado No 6)

A diferencia de lo que sucedió con otros puntos conflictivos, la postura oficial de la FAA de la época coincide con lo que plantean nuestros entrevistados en la actualidad. En ambos casos, sostienen que con el esfuerzo de su trabajo se financiaba al sector urbano-industrial por medio de las políticas de precios del IAPI. Es decir, las políticas del primer peronismo y las transformaciones sucedidas en el escenario internacional cambiaron el destino de la renta diferencial a escala internacional. Los chacareros arrendatarios se beneficiaron con el congelamiento de los arrendamientos que, sumado a la inflación de la etapa, resultó en una disminución del peso de la renta a pagar. Asimismo, los grandes terratenientes arrendadores vieron congelados los precios de los arrendamientos y su renta fue apropiada por el Estado y derivada al sector urbano industrial. Por otro lado, las empresas extranjeras de comercialización y transporte también dejaron de beneficiarse ya que fueron reemplazadas por el accionar del Estado (Flichman, 1984; Lattuada, 1986)

\section{Fomento financiero al sector rural}

El Banco Nación (BN) fue el encargado de articular las políticas económicas del gobierno nacional y el sector financiero para el agro. Fue el instrumento privilegiado para canalizar la mayor parte de las políticas de fomento tanto para los productores como para las cooperativas ${ }^{10}$. En concordancia con esto, todos los entrevistados lo recuerdan como el que estaba presente en la mayor parte de las localidades y canalizaba las políticas económicas del gobierno peronista, que "era el mejor banco que habia y que hay" ya que otorgaba créditos accesibles con facilidades de pago a los productores y fomentaba la producción agraria.

Lo que siempre fue una pata fundamental para las cooperativas fue el Banco Nación. Si no hubiese existido el BN muchas cooperativas no hubiesen existido. Esa es una realidad y hay que reconocerla. Y bueno, en su momento, estaba dirigido por el gobierno peronista, no es cierto? (...) En esta zona no me consta que haya habido una ayuda directa del gobierno, sí que estuvo el BN siempre presente; que en definitiva es una herramienta del gobierno (Entrevistado $\mathrm{N}^{\circ} 7$ )

Para poder llevar adelante esto, el gobierno nacional se apoyó en la Ley № 11.684 y otras disposiciones del año 1938 que desembocaron en la Ley No 12.389 que posibilitó la apertura de las Cajas Regionales de Préstamo y Ahorro. Se consolidó el posicionamiento del Banco y se profundizó la relación entre este y los productores otorgándoles directamente los créditos; se priorizó la capacidad de generación de riquezas y no el capital que tenían acumulado. Es decir, en base al análisis regional de los costos de cada cultivo se determinaba el índice de ganancia posible y así se estipulaban los créditos. Se buscó eliminar la intermediación del comerciante y acopiador, construyendo una relación directa entre los gerentes y los chacareros. Las sucursales que se encontraban en los distintos puntos del país desempeñaron un rol fundamental en este camino de acercar el crédito a los productores, profundizando las actividades desarrolladas por las que estaban ubicadas en la zona de campaña (Girbal-Blacha, 2003; Tumini, 2013)

En este contexto, en el año 1946, de acuerdo al Decreto Ley No 14.959, se estableció que el BN quedaba a cargo de la aplicación de la ley de Colonización No 12.636 y se incorporó el CAN que se convirtió en el principal dador de créditos hipotecarios, fomento a los pequeños y medianos productores y propietarios rurales, como así también a las cooperativas y explotaciones mixtas. El agro se constituyó como un espacio estratégico para el desarrollo de la economía peronista. Los créditos destinados al sector durante ese año crecieron un 39,7\%, y de ellos el 75\% fue otorgado a productores pampeanos. Sin embargo, este incremento fue menor al de los créditos destinados al comercio y a las actividades industriales durante el período del Primer Plan Quinquenal, etapa de plena implementación del modelo de Industrialización por Sustitución de Importaciones (Lattuada, 1986; Blanco, 2007; Barsky y Gelman, 2005; Girbal-Blacha, 2006; Tumini, 2013) 
Además, en ese momento, desde el gobierno se incentivó la mecanización del sector agropecuario apostando al fortalecimiento de la industria nacional, que para 1947 producía el 25\% de las cosechadoras, el $68 \%$ de los arados, el $17 \%$ de las sembradoras y el $85 \%$ de las rastras utilizadas por los productores. En épocas de crisis se otorgaron créditos especiales; por ejemplo en 1949 a productores trigueros y tamberos afectados por las sequías y las heladas tardías (Girbal-Blacha, 2003)

En esa época los productores se pudieron mecanizar porque había créditos muy baratos para maquinarias: al 3\% anual, después al 5\% anual, viste. Pero algunos decían: y, total te prestan la plata que es tuya. Viste, porque te compraban el cereal a 5 y lo vendían a 10. La gente que sacaba un crédito de 5 años al 3\% y con la pequeña inflación, cuando pagabas las últimas cuotas ya... lo que habías comprado era viejo y valía más que lo nuevo. Entonces la gente se fue armando de tractores nuevos (Entrevistado No 3)

El fomento al desarrollo y fortalecimiento de las cooperativas fue un objetivo del BN desde la década de 1930 que se profundizó en la etapa 1946-1955. Estas asociaciones eran claves ya que hacían de intermediarias entre el Banco y los productores. Para poder acceder a algunos créditos, los asociados presentaban sus carpetas en la cooperativa y esta hacía de intermediaria y/o garantía frente al BN. Un ejemplo son los créditos por planilla referencial.

\begin{abstract}
¿Qué es planilla referencial?
Vos ibas a la cooperativa y decías tengo X cantidad de maíz. Sumaban la cantidad esa y obtenías un crédito. Entonces vos, con esa planilla referencial que te la presentaba la cooperativa obtenías un crédito: que era la venta anticipada del cereal. Y después, cuando liquidabas el cereal tenías el plus del aumento del cereal. Le restabas los intereses y ganabas plata (...) Y había un crédito que se llamaba prefinanciación de exportaciones. Que es extraordinario el crédito. Cuando llega la época de la cosecha, generalmente los mercados, antes tal vez, yo eso no lo puedo afirmar, eran menos especulativos. Porque ahora las cosechas se juegan en Las Vegas, ahí se forma el precio, un mercado especulativo donde están circulando tres o cuatro cosechas y la real es una. Cuando se volcaba mucha oferta al mercado, mucha cantidad de volumen, el precio bajaba. ¿Entonces qué había? Había un crédito de bajo interés, generalmente era mucho más bajo que lo que vos esperabas que aumente el cereal. No sé si me explico (Entrevistado No 22)
\end{abstract}

En el año 1950 se produjo el cambio de rumbo de la política peronista, profundizándose la liberalización de la economía y, con él, la "vuelta al campo”. En 1952 comenzó la segunda presidencia de Perón, que presentó grandes cambios con respecto a la etapa anterior en diversos aspectos. El modelo económico cambió, "se privilegió la estabilidad sobre la expansión, la agricultura por sobre la industria, la iniciativa privada y el capital extranjero por sobre el crecimiento del sector público" (Torre, 2002, p. 64) En ese mismo año y ante la crisis económica, el gobierno implementó el Plan Económico de Emergencia que realizó un llamamiento a toda la sociedad para la reducción del consumo, el aumento de la producción y de la capacidad de ahorro. El Banco Nación flexibilizó los requisitos para el acceso a los préstamos agrarios con el fin de motorizar el desarrollo cooperativo y la mecanización del sector. Este plan contó con el apoyo y la colaboración de la SRA. El gobierno logró frenar la inflación pero no aumentar los saldos exportables. (Giuliani, 2008; Blanco, 2007; Lázzaro, 2015; Olivera, 2015; Girbal-Blacha, 2006; Mateo y Olivera, 2006; Mateo, 2006)

En 1952 se proyectó y entró en funcionamiento el Segundo Plan Quinquenal ${ }^{11}$ (1952-1957) A través de él el gobierno buscó consolidar su política agropecuaria planteándose diferentes acciones. El Plan Económico de Emergencia se anunció en febrero de 1952 y estuvo vigente hasta el año siguiente. A mediados de 1953, se puso en marcha el Segundo Plan Quinquenal manteniendo los objetivos y algunas líneas de intervención del Plan anterior.

En este contexto, en la localidad de Tortugas, a partir de un crédito otorgado por el BN, el CCP adquirió las instalaciones de la firma Santilli Hnos. para instalar ahí sus oficinas comerciales y centro de acopio.

En el caso de la cooperativa de Los Molinos, también se solicitaron créditos al BN que fueron otorgados. En la reunión del Consejo Directivo realizada 25 de octubre de 1952 "se resuelve certificar firmas a fines de abrir cuenta corriente en el Banco Nación Argentina de Rosario”(Acta No 45) Además, en la reunión que realizaron el 11 de julio de 1953 "se resuelve presentar al Banco Nación Argentina sucursal Casilda 
la papelería indispensable para solicitar el otorgamiento del Crédito Bancario" (Acta $\mathrm{N}^{\circ} 58$ ), el cual fue solicitado por el monto de $\$ \mathrm{~m} / \mathrm{n} 80.000$ (Acta No 62 CD, 12 de septiembre de 1953) El Consejo Directivo, el día 05 de noviembre de 1953 (Acta No 65 CD) acepta las condiciones ${ }^{12}$ del Banco Nación para el otorgamiento del crédito, decisión que se pone a consideración de la Asamblea General Ordinaria celebrada el día 14 de febrero de 1954.

El Banco de la Provincia de Santa Fe (BPSF) no estuvo ajeno a esta orientación de promoción del sector agrario. En el año 1938, de acuerdo a la Ley No 2.721, se creó la Sección “Crédito Agrario" con la que se inauguró una etapa de política orgánica en la materia. La misma se encargaba de préstamos a productores a corto y mediano plazo sin garantías hipotecarias para financiar aquellas labores incluidas en el ciclo productivo. Sin embargo, el crédito destinado al agro ocupaba el $3^{\circ}$ lugar, luego de los destinados a comerciantes y empleados (Tumini, 2013)

Para mediados de la década de 1940, las líneas de fomento al agro se consolidaron. En 1946, por un lado, se establecieron nuevas sucursales del BPSF en el territorio provincial. Por otro lado, y de acuerdo al Decreto No 11.186, se transformó el sistema financiero y se reglamentó la sección Crédito Hipotecario según lo establecido por la recién mencionada Ley No 2.721. Así, los créditos estuvieron destinados a agricultores, ganaderos y cooperativas agrícola-ganaderas para la compra de tierra o para la cancelación de deudas originadas en esta compra; los más importantes fueron los préstamos especiales para cosecha de trigo, lino, maíz y girasol. Los créditos destinados al agro se incrementaron exponencialmente en el período 1938-1956, llegando a ocupar el primer lugar como sector receptor, representando el 55.56\% (\$14.964.300) del total de créditos del año 1955. Estos fueron otorgados por las sucursales ubicadas en el interior de la provincia que dependían de las centrales de Rosario y Santa Fe, pero no por ellas, lo que demuestra la importancia que estas casas tuvieron en la intención de acercar a los productores al sistema financiero (Tumini, 2013)

\section{Política de tierras}

El modelo de desarrollo agrario pampeano se cimentó sobre el sistema de arrendamiento. De acuerdo a estimaciones realizadas por el CNA de 1937, más del 60\% de los productores santafesinos eran arrendatarios y su mayoría no tenía contrato formal. Muchos de ellos se asentaban en tierras de los terratenientes que combinaban entre sus actividades productivas la agricultura con la ganadería. Estas familias arrendatarias quedaban a merced de los intereses y voluntad de los terratenientes. Las condiciones de trabajo y de vida que les imponían eran muy duras. Así, la inestabilidad, la precariedad y la falta de certidumbres -más allá de los riesgos propios de la actividad- eran comunes. Las condiciones de los contratos de arriendo son descritas como "leoninas".

$\mathrm{Al}$ arrendatario no lo dejaban mucho tiempo en el campo, cada dos años o tres a lo sumo lo cambiaban de campo. Venían un día y por un motivo o por otro lo sacaban, tenía que ir a otro campo. Los que eran propietarios tenían un hogar bien hecho, una casa bien hecha, con un buen monte, una buena sombra, que se yo, con árboles. Y el arrendatario era alguien que como andaba de una chacra a la otra, porque cada 2 o 3 años lo echaban, no plantaba ni siquiera una planta, ni un árbol, porque sabía que cuando podía tener algún beneficio de ese árbol tenía que dejarlo, levantarse e irse. Entonces cuando se iba no se le reconocían nada, porque a nosotros nos pasó eso (Entrevistado № 17 )

Antes éramos casi esclavos en el campo porque te cobraban lo que querían, ¿no le gusta? ¡Váyanse! Por eso yo me hice peronista, mi padre también peronista... se consiguió muchos derechos en el campo porque éramos muy explotados, esos Bunge y Born ${ }^{13}$ eran unos hijos de su buena madre. Tenían a los mayordomos, a los administradores y mandaban ellos. ¿Le gusta? Es así. Nos mandaban a cortar yuyos debajo del alambrado con calor... Y después yo, cuando empecé a trabajar, ya estaba cambiando, vino Perón (Entrevistado No 13)

La utilización de diversas formas de arriendo le garantizaba al terrateniente la obtención de una renta, dejaba en manos del arrendatario todos los riesgos propios de la actividad y el ingreso del productor dependía 
de lo que este fuera capaz de producir. Además, a diferencia del trabajador asalariado, poseía un costo variable que se determinaba de acuerdo al precio del producto (Sábato, 1979) Así, hasta la Primera Guerra Mundial (PGM), el sistema benefició al arrendatario porque la escasez de fuerza de trabajo habilitó la posibilidad de mejores condiciones contractuales y de cierta apropiación de renta preferible a la compra de parcelas, ya que esto implicaba la inmovilización del capital. Sin embargo, con la PGM, aumentó la inmigración, la disponibilidad de mano de obra y las condiciones de arriendo se volvieron más duras. Se congeló también la oferta de tierras por el agotamiento de la frontera agrícola, lo que llevó a un aumento de su precio (Hora, 2005)

La vida de los chacareros arrendatarios quedaba atada a la voluntad y decisión del propietario, tanto en lo cotidiano como en lo que respecta a las decisiones de producción. Así, debían proveerse en los almacenes que los propietarios decían, comercializar la producción donde estos querían y, además, elegía primero el grano del cual cobrar su deuda. Muchas veces coincidía en una sola persona física el gran propietario, el dueño del almacén de ramos generales y el acopiador o cerealista.

Por ejemplo no podían tener padrillos ellos, tenían que hacerlo llevar a las yeguas a la estancia a servir y les cobraban el servicio. Y si tenían vacas tampoco podían tener toros, tenían que llevar a las vacas cuando entraban en celo y le cobraban el servicio del toro (Entrevistado No 16)

Mi madre siempre nos decía que estaba cansada de andar por las calles, con todas las cosas a cuesta, cargando todo arriba de la chata, llevándonos todo de un campo a otro, porque nos echan de los campos. En esa época nosotros estábamos en un campo que el dueño también era cerealista (Entrevistado No 17)

La condición de pequeños y medianos propietarios y arrendatarios fue base de solidaridad entre muchos productores, ya que cuando eran desalojados de las estancias donde estaban ubicados eran alojados algún tiempo en los campos de los primeros.

Muchos croatas vivían en carpa en el campo sería de mi bisabuelo porque era el que tenía propiedad. Entonces, cuando los sacaban del campo es como que los tenía ahí. Vivían en carpas (Entrevistado No 15)

En este contexto, las acciones propuestas por Perón durante la campaña electoral de 1946, que delineaban una reforma agraria, alarmaban a los grandes propietarios y alentaban el apoyo de los pequeños y medianos productores. A partir de su triunfo electoral, estas acciones no se inscribieron estrictamente dentro de una reforma agraria. La planificación, si bien incidió sobre la estructura agraria (Lattuada, 1986), apuntó a un aumento sostenido de la productividad. Podemos decir que,

los parámetros de la política agraria peronista combinaron medidas económicas, política de tierras y concesiones laborales para dar respuesta a una 'creciente presión nacional sobre la tierra', que pretendía lograr un aumento sostenido de la producción para beneficiar a los sectores priorizados por el Primer Plan Quinquenal (Mateo y Olivera, 2006, p. 105)

Pero el discurso en contra del latifundio tuvo implicancias, fue el que habilitó la posibilidad para que muchos no propietarios pudieran tener una oportunidad, como es el caso de uno de nuestros entrevistados. Nos contaba que

Llegamos a propietarios porque loteó la mujer, porque ese campo fue de Bunge Born, ese campo fue una estancia. Bunge Born tenía un accionista que era... como era... Bemberg y falleció y tenía una hija. Y la hija quiso retirarse, quiso la sucesión. Y como era accionista le dieron la estancia esa. Y después ella quiso lotear y estaba el tiempo de Perón y vio que había lío, que esto, que lo otro, que quería expropiar y dieron créditos ellos mismos a nosotros y a muchos más y así fue (Entrevistado $\mathrm{N}^{\circ} 13$ )

Las políticas en torno al arrendamiento profundizaron las medidas que se venían implementando desde principios de la década de $1940^{14}$, prorrogando la baja de la tarifa de alquiler y la suspensión de los juicios de desalojo. En 1942, bajo la presidencia de Ramón Castillo, se sancionó la Ley No 12.771 que redujo el canon a pagar en especie o dinero y suspendió los desalojos hasta finalizada la Segunda Guerra Mundial, con el fin de evitar los éxodos rurales de los años anteriores. Esta fue la primera ley que limitó la renta por locación del suelo y la llamada libre contratación (Lattuada, 1986; Girbal-Blacha, 2007) 
Con estas medidas se pretendió evitar la expulsión de los arrendatarios de las tierras como resultado del paso del uso del suelo de la agricultura hacia la ganadería. También se buscó aliviar los efectos de la caída de los precios agrícolas y el diseño de una política de colonización que permitiera el acceso de los productores a la tierra. Todo esto se realizó en un marco de gran conflictividad social con la intención de beneficiar a diferentes actores y atenuar los posibles conflictos. Fue una válvula de escape para los propietarios, ya que permitía establecer contratos accidentales (Blanco, 2007; Lázzaro, 2015) Como señala Blanco,

se fue diseñando, entonces, una política agraria reformista distinta que apuntaba a lograr una más equitativa distribución de la propiedad rural en respuesta de la creciente conflictividad rural no siempre manifiesta pero al menos potencial, producto de los problemas que estaba atravesando. Sin embargo, las medidas adoptadas no pasaron del diseño de nuevas condiciones de arrendamiento y de una política de colonización de lenta aplicación (Blanco, 2007, p. 55)

Con estos decretos, se logró fijar a los arrendatarios a la tierra pero no se solucionaron los problemas de inversión y se profundizaron los conflictos entre terratenientes y arrendatarios. Los primeros aceleraron el proceso de subdivisión de las propiedades por medio de sociedades anónimas que sirvieron para mantener la propiedad en las mismas manos y los arrendatarios reclamaban al Estado la expropiación de las tierras (Lattuada, 1986)

La mayoría de los entrevistados recuerdan la Ley No 13.246. Esta disposición, sumado a la alta inflación de la época y a los créditos accesibles del Banco Nación y/o del Banco Hipotecario, permitió que muchos arrendatarios pudieran convertirse en propietarios. Todo esto es considerado como mejoras en la situación de los pequeños y medianos productores agropecuarios, sobre todo para los arrendatarios. Estos beneficios son atribuidos directamente al $\mathrm{BN}$ y, muchas veces, no son relacionados con las políticas peronistas de fomento al sector agropecuario que utilizaba a esa entidad financiera como canalizadora.

Los chacareros que eran arrendatarios eran peronistas porque con la ley por ejemplo de arrendamiento, la 13.246, que fue en esa época una ley progresista, se evitaron los desalojos, se congelaron los arrendamientos por un montón de años y bueno... entonces los chacareros empezaron a ver algún mango, porque si no antes se lo llevaba todo el dueño del campo (Entrevistado No 1)

A nosotros nos benefició una inflación galopante que vino, diríamos, en el segundo gobierno de Perón vino una inflación tremenda y un poco visionarios o que se yo... la suerte diríamos, nos abrió el ojo un poco y empezamos a capitalizarnos. Compramos el primer campito que mi madre iba de susto en susto (...) Se nos ocurrió comprar un campo, ¡bendita es esa idea! Vino un día un comisionista a mi casa y dijo: ¿no se animan a comprar un pedacito de campo? Habló con mi hermano, como él era mayor... estábamos en el campo, arando, se araba con caballos, no había tractores, tractores tenía la genta que estaba bien o que se yo... tractores a lo mejor había en el campo pero solamente se usaban en tiempo de cosecha cuando había apuro de trabajar o para arrastrar a las cosechadoras (...) Mi madre dice: con que van a comprar que hay días que tenemos que ajustarnos, que gracias a que tenemos pollos, la quinta, que sino no tenemos para comer! ¿Con qué van a comprar el campo? Mira vieja - porque mi hermano le decía así- si no nos jugamos esta vez, no nos jugamos más. Yo calculo que va a ser difícil pero un poco nos ayudará la cooperativa, otro poco nos ayudará el cerealista y, bueno, lo compramos supeditado a un crédito que pueda haber, buscaremos algún amigo que tenga algún peso encima y nos preste (...) Compramos 60 ha.(Entrevistado No 17)

Mario Lattuada (1986) sostiene que el acceso a la propiedad de la tierra sucedido durante esta etapa generó un cambio de magnitud en la estructura social agraria; a tal punto, que la considera una etapa de colonización tan importante como la de la segunda mitad del siglo XIX. Durante esta etapa, se deterioró el poderío de la clase terrateniente sin eliminar su base de sustentación: la propiedad privada de la tierra. Por su parte, Silvia Lázzaro (2015) plantea que, durante el período 1940/60, como derivación de las políticas de arrendamiento, hubo un incremento de tierras en propiedad y una disminución del arrendamiento. Esto no necesariamente refleja que todos los arrendatarios se convirtieron en propietarios, los más pobres sostiene la autora- abandonaron la producción y se proletarizaron en las urbes. Los que tuvieron capacidad de capitalizarse pudieron comprar las tierras. De los que ya poseían, algunos se tecnificaron y se ampliaron hacia el contratismo de labores para luego convertirse en contratistas de producción. Además, se modificó la conducta del terrateniente por el desarrollo del contratismo rural (es decir, se contrata servicio en detrimento 
del arriendo de tierras) y la ampliación de las formas mixtas de propiedad articulada con la recomposición del latifundio ganadero. Todo esto dio como resultado la reforma de la tenencia, lo que según Perón fue calificado como 'reforma tranquila', sin modificar estructuralmente el régimen vigente (Lázzaro, 2015)

\title{
Encuentro cooperativistas - Perón
}

En las actas revisadas se encuentran diversos registros señalando que se formaron delegaciones de socios para asistir a reuniones con Perón y con otros miembros de su gobierno, se enviaron telegramas, adhesiones y solicitudes al gobierno nacional, mencionando el nombre del entonces Presidente de la Nación: Juan Domingo Perón. Hechos que no fueron registrados mencionados en las entrevistas.

Así, el Consejo de Administración de la cooperativa de Los Molinos en el Acta No 43 con fecha 04 abril de 1952, informa que

\begin{abstract}
Se dio lectura a la comunicación del Consejo Directivo y consultivo No 181 en la cual se citan a los Directores de Cooperativas para que asistan a Buenos Aires a una reunión precedida por el general Perón, correspondiendo a la misma fueron designados los miembros Sres. Luciano Screpanti y Guido Caciarelli ${ }^{15}$ para que hagan acto de presencia en representación de nuestra cooperativa.
\end{abstract}

En la reunión del día 15 de agosto de 1953 "se resuelve enviar un telegrama al Gral. Perón adhiriéndose al Memorial presentado por la Federación Agraria solicitando modificación impuesto a los réditos (Acta No 59 CA)" En el Acta No 81, con fecha 24 de julio de 1954, se registró la designación de un representante para asistir a una reunión con el Presidente Perón para tratar la bonificación sobre los quintales de maíz y la forma de distribución de los tractores Zetor. En la Asamblea General Extraordinaria realizada el 10 de abril de 1954 se dejó asentado "sean enviados sendos telegramas al Sr. Pte. De la Nación Gral. Juan Perón y el Sr. Ministro de Comercio Exterior Sr. Antonio Caffiero solicitando la eliminación de los acopiadores en las localidades donde existan Cooperativas (Acta No 8)"

No hay registro de la respuesta obtenida a dicha solicitud en ningún acta posterior, como así tampoco del cierre de algún acopio privado como consecuencia de la misma. Por otra parte, el día 10 de julio de 1954 se realizó en el Centro Cooperativo Primario (CCP) Tortugas una Asamblea general de la que participaron los asociados de Agricultores Federados Argentinos (AFA) ${ }^{16}$ y los de la FAA; también estaba presente el delegado de su Central. El mismo les pide a los asociados presentes que participen de forma responsable en el Censo Periódico Informativo que estaba llevando adelante dicha entidad ya que obtendrán datos estadísticos tendientes a lograr un Plan Agrario fomentado por nuestra Entidad, en concordancia con el apoyo que presta en todos los casos el Exmo. Señor Presidente de la Nación General Juan D. Perón.” Acta No 11)

Otro registro aparece en el Acta No 29 del 04 de septiembre de 1955, en la que se asienta que el Auditor de AFA, presente en la Asamblea, informa a los socios asistentes sobre el memorial enviado al Presidente de la Nación en el que se describen

los serios problemas que está soportando el agro Argentino, los continuos y elevados aumento [sic] en todos los rubros de la producción, en lo que respecta a la contribución obligatoria de los productores a la Confederación General Económica, el Señor López [sic] pone en conocimiento de la Asamblea que el Poder Ejecutivo de la Nación [sic], dispuso ya eximir a los productores de dicha obligación, concediendo a Coninagro la Personería Gremial, a continuación la Asamblea mociona por unanimidad elevar un telegrama al C.D. Central apoyando los conceptos vertidos en el mencionado Memorial (Acta No 29)

Los hechos descriptos en las actas no fueron registrados por los entrevistados, no fueron mencionados en las entrevistas. Si algunos de ellos estuvieron presentes en las asambleas o reuniones de Consejo Directivo que se mencionan y sus firmas aparecen rubricando las actas correspondientes, ¿̨por qué no se mencionan estos hechos?; ¿qué es lo que hace que no recuerden que un compañero suyo asistió a un encuentro con el Presidente de la Nación? Esto nos lleva a otros interrogantes: ¿una tradicional oposición al peronismo facilita 
este olvido o esta desvalorización de determinados hechos y circunstancias? $\mathrm{O}$, ¿̨es el presente que se asoma desde el pasado y lo reescribe?, ¿el enojo con el gobierno vigente, que pudimos corroborar en momentos de hacer las entrevistas, tamizó su visión del pasado?

En estos relatos, quizás, sea importante considerar lo planteado por Portelli (2003), quien sostiene que en las entrevistas aparece un yo que relata los cambios a partir de pequeños acontecimientos sin macro referencias políticas y económicas. Así, forma parte de la interpretación relacionar las representaciones de los actores con las condiciones estructurantes, y a su vez, respetando sus puntos de vista.

\section{REFLEXIONES FINALES O “TODO ES RESULTADO DE NUESTRO ESFUERZO”}

Para finalizar nos interesa remarcar que la noción de tiempo bistórico es fundamental para poder comprender los relatos recogidos; nos presenta la articulación entre tiempo pasado -en tanto hecho sucedido- y tiempo presente -en tanto hecho que se está narrando-. Así, pasado y presente se conjugan en la construcción de una narrativa, de una historia de vida tanto individual como de un grupo social. El tiempo histórico y el tiempo biológico se funden en una narrativa que reconstruye la historia de la expansión del cooperativismo agrario en el sur de la provincia de Santa Fe. Ese relato está permeado por el transcurrir de la vida del narrador; uno no recuerda sólo lo que pasó sino que el devenir del tiempo decanta los hechos y permite recordarlos, olvidarlos y significarlos de diferentes maneras.

Los entrevistados perciben el período del peronismo histórico como conflictivo. Por un lado, recuerdan una etapa de crecimiento económico, posibilidades de mecanización, mejoras en la calidad de trabajo y de vida. Por otro lado, lo perciben como un período intervencionista, autoritario, poco democrático. Recuerdan como un aspecto negativo la política laboral, en lo que respecta al empoderamiento de los sindicatos rurales y concesiones respecto al acceso de los derechos que atentaban contra su propia estrategia productiva. Este nuevo lugar de los sindicatos representaba para los chacareros la intromisión en sus chacras, en el quehacer cotidiano y, concretamente, la imposibilidad de realizar trabajos físicos ellos o sus familias.

También reconocen un fuerte intervencionismo del gobierno en la política de comercialización de granos, canalizada por intermedio del IAPI. Es interesante plantear que muchos lo señalaban como un punto de encuentro con el gobierno de Cristina Fernández (2007-2015), durante el cual se sucede el conflicto en torno a la Resolución No 125 que establecía las retenciones a las exportaciones. En esta comparación, los entrevistados que reconocían que en ambos momentos había intervencionismo económico también hacían la salvedad que durante el peronismo histórico existían acciones de fomento para el agro, situación que en la actualidad no se visualizaban.

En este marco, la cooperativa es considerada fruto del esfuerzo propio y no se asocia directamente con el fomento sucedido durante los primeros gobiernos peronistas. Se diferencia dicho período con lo sucedido durante el gobierno de facto de la Junta Militar (1976-1983) y el período comprendido bajo las presidencias de Carlos Menem (1989-1999), dos etapas que fueron muy duras para el movimiento cooperativo. En esta línea, los entrevistados sostienen un relato que valoriza el esfuerzo propio, el ascenso social a partir del trabajo y el sacrificio realizado sin la ayuda de nadie, de ningún gobierno ("todo lo logré solo, con la ayuda de mi familia"), sólo de la cooperativa que estuvo presente acompañándolos en este camino ("a ese lo ayudamos a sacar la cabeza del barro")

En las entrevistas no aparece en ningún momento referencia alguna respecto a la relación entre las cooperativas y el gobierno. Todos los entrevistados coincidieron en señalar que las cooperativas de comercialización en la región se hubieran conformado igual más allá del fomento brindado por el gobierno de turno, en este caso el peronista. Atribuyen al esfuerzo propio el haber logrado unirse en la figura de la cooperativa, y a la ACA y a la FAA como las entidades que alentaban a los productores y los contenían y asesoraban en la temática. Señalan que fue importante el apoyo que se recibió bajo el gobierno peronista 
pero no se menciona como un factor determinante a la hora de encontrar las razones que posibilitaron su expansión.

Algunos entrevistados sí reconocen que desde el gobierno peronista se incentivó la formación de cooperativas, "Perón aconsejaba que tenían que formarse las cooperativas, ese era el lema de él. Perón le dio una mano muy grande al campo, le dio una mano grande pero viste... después todo cambió (Entrevistado No 16)"

El entrevistado No $^{\circ} 17$ aclara que si bien es cierto que sucedió esto

aquí no se formó por el peronismo ni por el radicalismo, se formó por un grupo de esa gente que dijeron vamos a formar una cooperativa. Tenían una visión de las cosas, un poco escuchando el consejo desde el principio del gobierno y además la FAA que siempre apoyando, tratando de apoyar que se crearan las cooperativas. Les salió bien porque se pusieron a trabajar y a trabajar bien (Entrevistado No 17)

Nos parece importante aclarar que el Entrevistado No 16 posee una trayectoria política en el Partido Justicialista, habiendo sido secretario por el mismo en su localidad. Por su parte, el entrevistado $\mathrm{N}^{\circ} 17$ se define a sí mismo como "apolítico", "apartidario", y como alguien que reconoce al buen funcionario. En esta línea, reconoce los logros y avances en materia social promovidos desde el peronismo, manteniendo cierta distancia ideológica con el mismo.

Los entrevistados coinciden en que siempre es importante el apoyo del gobierno nacional para el sostenimiento del movimiento, y que en los momentos en que los gobiernos no apoyaron explícita o implícitamente a las cooperativas estas tuvieron dificultades para su funcionamiento. Señalan como un momento de crisis de los chacareros a la etapa de los gobiernos menemistas (1989-1999) en el que se consolidó el proceso de concentración tanto de la tierra como de la producción, donde además desaparecieron miles de pequeños y medianos productores y con ellos sus cooperativas. "Las primeras estimaciones del CNA 2002 arrojaron para la provincia (de Santa $\mathrm{Fe}$ ) 27.142 explotaciones con una superficie agropecuaria total de 10.893.661 ha, en términos absolutos 9.720 explotaciones (26\%) y 180.581 ha menos que en el CNA 88 " (Cloquell, Albanesi, De Nicola, González, Preda y Propersi, 2003, p. 39)

\section{Bibliografía}

Barsky, O. y Gelman, J. (2005) Historia del agro argentino. Desde la Conquista hasta fines del Siglo XX. Buenos Aires: Editorial Mondadori.

Batista, G. (2010) Abstract Tesis de su Doctoral "Memoria e Identidad de la clase trabajadora durante la resistencia peronista” Presentado en el Segundo Congreso de Estudios Sobre Peronismo

Bertaux, D. (2005) Los relatos de vida. Perspectiva etnosociológica. Barcelona: Edicions Ballaterra.

Blanco, M. (2007) Reforma del agro pampeano. Arrendamiento, propiedad y legislación en la provincia de Buenos Aires 1940-1960. Buenos Aires:Universidad Nacional de Quilmes.

Bourdieu, P. (1987) De las reglas a las estrategias en Autor, Cosas Dichas, Barcelona: Editorial Gedisa, págs. 67-82

Cloquell, S., Albanesi, R, De Nicola, M., González, M., Preda, G. y Propersi, P. (2003) Las unidades familiares del área agrícola del sur de Santa Fe en la década del noventa. Revista Interdisciplinaria de Estudios Agrarios, 19.

Ehrlich, L., (2008) "El peronismo rebelde en dos tiempos: entre el cambio generacional y la memoria" En Revista Prácticas del oficio. Investigación y reflexión en ciencias sociales, (3) Recuperado en: http://ides.org.ar/wpcontent/uploads/2012/04/artic241.pdf

Flichman, G. (1984) La renta del suelo y el desarrollo agrario argentino. Buenos Aires: Editorial Siglo XXI.

Girbal-Blacha, N. (2003) Mitos, paradojas y realidades en la Argentina peronista (1946/1955): una interpretación histórica de sus decisiones político-económicas. Buenos Aires: Universidad Nacional de Quilmes. 
Girbal-Blacha, N. (2006) Discursos confrontados. Realidades en tensión. El cooperativismo agrario y la política económica del Estado Peronista (1946-1955) En Olivera, G. (comp.), Cooperativismo Agrario: Instituciones, Políticas Públicas y Procesos Históricos (pp. 21-57)Buenos Aires: Ferreira Editores.

Girbal-Blacha, N. (2007) Las representaciones agrarias y el Estado (1930/1955) Continuidades y cambios en el imaginario colectivo argentino. En Girbal Blacha, N. y Mendoça, R. (coord.), Cuestiones agrarias en Argentina y Brasil (pp. 223-247) Buenos Aires: Prometeo Editorial.

Giuliani, A. (2008) Conformación y límites de la alianza peronista (1943-1955) En S. De Luque, et. al. Pasados presentes: política, economía y conflicto social en la historia argentina contemporánea (pp. 161-198) Buenos Aires: Editorial Dialektik.

Hora, R. (2005) Los terratenientes en la pampa Argentina. Una historia social y politica, 1860-1945. Buenos Aires: Siglo XXI Editora Iberoamericana.

James, D., (2004) Doña María. Historia de vida, memoria e identidad política. Buenos Aires: Ediciones Manantial.

Kofman, M., Lanciotti, N. y Pérez Barreda, N. (2012) La industria santafesina desde la expansión agraria a la diversificación productiva, 1887-1964. En C. Frid y N. Lanciotti (comp.), De la expansión agraria al desarrollo industrial: la economía de Santa Fe entre 1850 y 1970 (pp. 160-205) Rosario: Prohistoria Ediciones.

Lattuada, M. (1986) La política agraria peronista (1943-1983)/1. Buenos Aires: Centro Editor de América Latina S. A.

Lattuada, M y Renold, JM (2005) El cooperativismo agrario en la Argentina. Evolución económica y social En Revista Pampa, 1(1), 55-86. doi:https://doi.org/10.14409/pampa.vli1.3120

Lázzaro, S. (2015) La política agraria del peronismo. El acceso a la propiedad de la tierra: arrendamientos y colonización. En Graciano y Olivera (coord.), Agro y politica en Argentina. Tomo II: Actores sociales, partidos politicos e intervención estatal durante el peronismo. 1943-1955 (pp. 135-195) Ciudad Autónoma de Buenos Aires: Fundación CICCUS.

Mascali, H. (1986) Desocupación y conflictos laborales en el campo argentino (1940-1965) Buenos Aires: Centro Editor de América Latina.

Mateo, G. (2005) El corporativismo rural frente a la política agraria peronista: SRA-FAA-ACA. En S. Lázzaro y G. Galafassi (comp.) Sujetos, politica y representaciones del mundo rural. Argentina 1930-1975 (pp. 119-164) Buenos Aires, Siglo XXI Editores.

Mateo, G. (2006) La educación cooperativa: entre la doctrina y la experiencia, entre las políticas públicas y las prácticas institucionales (1940-1955) En Olivera, G. (comp.), Cooperativismo Agrario: Instituciones, Politicas Públicas y Procesos Históricos (pp. 59-81)Buenos Aires: Ferreira Editores.

Mateo, G. y Olivera, G. (2006) Corporaciones agrarias y cooperativismo en la Argentina (1946/1955) Un estudio comparativo entre la Federación Agraria Argentina (FAA) y la Asociación de Cooperativas Argentinas (ACA) En Olivera, G. (comp.), Cooperativismo Agrario: Instituciones, Políticas Públicasy Procesos Históricos (pp.83-119) Buenos Aires: Ferreira Editores.

Olivera, G. (2004) Los proyectos cooperativos de la Federación Agraria Argentina (primera mitad del Siglo XX) En G. Galafassi (comp.), El campo diverso. Enfoques y perspectivas de la Argentina del Siglo XX (pp. 49-67)Buenos Aires: UniversidadNacional de Quilmes.

Olivera, G. (2006) Corporaciones agrarias y cooperativismo en la Argentina peronista (1946-1955) Un estudio comparativo entre la Federación Agraria Argentina (FAA) y la Asociación de Cooperativas Argentinas (ACA) En Autor (comp.) Cooperativismo Agrario: instituciones, politicas públicas y procesos históricos (pp. 121-151) Córdoba: Ferreyra Editor.

Olivera, G. (2015) Cooperativas y gremios chacareros como piezas claves en la política agraria peronista En O. Graciano y G. Olivera (coord.) Agro y politica en Argentina. Tomo II: Actores sociales, partidospoliticos e intervención estatal durante el peronismo. 1943-1955 (pp. 197-268) Ciudad Autónoma de Buenos Aires: Fundación CICCUS.

Peirano, N., (2003) Ciudadanía femenina en el testimonio de una trabajadora En Anuario No 5, Facultad de Ciencias Humanas de La Plata.

Pollak, M. (2006) Memoria, olvido y silencio. La Plata: Ediciones Al Margen. 
Portelli, A. (2003/04) El uso de la entrevista en la historia oral en Historia, memoria y pasado reciente. Anuario, 20. Escuela de Historia, UNR, 35-48.

Renold, J. M. (1995), Estructura y Organización cooperativa en el campo argentino. Un análisis antropológicoinstitucional, Rosario: Editorial Magíster

SABATO, J.F. (1979) Notas sobre la formación de la clase dominante en la Argentina moderna (1880-1914) Buenos Aires: CISEA

Sautu, R., Boniolo, P, Dalle, P. y Elbert, R. (2005) Manual de metodologia: construcción del marco teórico, formulación de los objetivos y elección de la metodología. Buenos Aires: Consejo Latinoamericano de Ciencias Sociales (CLACSO)

Sidicaro, R. (1982) "Poder y crisis de la gran burguesía agraria argentina" En A. Rouquié (comp.) Argentina, hoy. Buenos Aires: Siglo XXI Editores.

Sigal, S. y Verón, E. (1982) Perón: discurso político e ideología. En Rouquié, A. (comp.), Argentina, hoy (pp. 151-205) Buenos Aires: Siglo XXI Editores.

Svampa, M. (2006) Civilización o Barbarie. El dilema argentino. Buenos Aires: Editorial Taurus.

Torre, J. C. (2002) Introducción a los años peronistas. En Torre, J. C. (Dir.), Los años peronistas (1943-1955) Nueva Historia Argentina, Tomo VII (pp. 12-77) Buenos Aires: Editorial Sudamericana.

Tumini, E. (2013) La intermediación cerealera y el crédito agrícola. Racionalidad empresarial en un periodo de cambio 1910-1955 (Tesis doctoral) Universidad Torcuato Di Tella, Buenos Aires.

\section{Notas}

1 Desde una perspectiva de análisis institucional se pueden consultar, entre otros, los trabajos de: Renold 1995, Lattuada y Renold 2005, Olivera 2004, 2006.

2 Entre los trabajos que analizan las políticas públicas, se pueden consultar: Blanco 2007, Girbal-Blacha 2003, Lattuada 1986, Mateo 2005.

3 Entre otros estudios que abordan al peronismo desde la historia oral, pueden consultarse los siguientes: James 2004, Peirano 2003, Batista, 2010, Ehrlich 2008.

4 En el año 1948 se fundó la Cooperativa Agrícola Ganadera de Armstrong, en 1950 se fundaron la Cooperativa Federal Agropecuaria de Chañar Ladeado y la cooperativa de Los Molinos; todas con el apoyo de la FAA. En 1951 se fundó el CCP de Casilda y en 1953 el de Tortugas, ambos de AFA. En ese mismo año, con el auspicio de la ACA, se fundaron la cooperativa de la localidad de Zavalla como así también la Cooperativa Agropecuaria de Armstrong (CADAL)

5 Optamos por el periódico La Tierra porque la mayor parte de las cooperativas seleccionadas, así como los entrevistados, participaban de la FAA en el período de análisis (1946-55)

6 El habitus es el esquema de percepción, apreciación y acción por medio del cual los agentes perciben al mundo social. Es un esquema de producción de prácticas y un sistema de percepción y apreciación de las prácticas en los cuales se refleja la posición desde la que se construye (Bourdieu, 1987)

7 Si bien no se encuentra contenido estrictamente en el período considerado en este artículo, ya que fue sancionado dos años antes de la asunción de Perón como presidente de la Nación, es importante tenerlo en cuenta dado el impacto que provocó en el sector: por un lado, mejorando las condiciones de vida de los beneficiarios y, por otro lado, por la gran controversia que suscitó dentro del sector patronal.

8 Institución creada en 1866 por un grupo de propietarios rurales como defensa gremial de los intereses de los grandes terratenientes argentinos. Tuvo presencia activa en muchos gobiernos nacionales, sobre todo en el Ministerio de Agricultura. Se trataba de un grupo de empresarios innovadores y no tan importantes en número de hectáreas o animales; presentaban al sector como el más dinámico de la burguesía argentina (Hora, 2005) Esta institución se declaraba abiertamente contra todo tipo de intervencionismo estatal y de las políticas de protección de los asalariados rurales ya que consideraban que no tenían en cuenta la naturaleza del trabajo agrario. Asimismo, se declaraban a favor de la libre regulación del mercado, la profundización de la especialización del modelo agroexportador y de soluciones liberales para los problemas de la economía nacional (Sidicaro, 1982)

9 General Roca es una localidad de la provincia de Córdoba que se encuentra a $15 \mathrm{~km}$ de Tortugas.

10 El BN poseía diversas líneas crediticias: hipotecarios para compras de inmuebles, mejoras y cancelación de hipotecas; cuestiones relacionadas a la producción como gastos de siembra, reposición de animales de labor, compra de hacienda de cría y lecheras; mejora de la calidad de vida o subsistencia de la familia rural. También realizaba otros tipos de ayudas financieras como la adquisición y distribución de semillas y bolsas, provisión de medios para combatir las plagas, rebaja 
en los fletes ferroviarios y créditos accesibles y blandos para compra de maquinaria agrícola. Se otorgaron créditos a "firmas de escasa o ninguna responsabilidad material, pero de reconocida capacidad y solvencia moral" (BNA, Memoria y balance general correspondiente al año 1950, Buenos Aires 1951, p. 51. En Girbal-Blacha, 2003, p. 123)

11 Entre las medidas principales se encontraban: colonización y reordenamiento del uso de la tierra para incorporarlas al sistema productivo; incentivos a la mecanización de la producción agropecuaria; fomento a la investigación agropecuaria tanto en el Estado como en el sector privado, generación de espacios de asistencia técnica y educación agropecuaria para los productores; generación de un sistema impositivo que presione a los propietarios a hacer un uso productivo de sus tierras; reordenamiento de los centros de conservación y distribución de la producción agropecuaria; fomento de la industria agropecuaria, principalmente mediante cooperativas, para la manufacturación de los productos primarios. Se profundizaron las líneas de crédito para el acceso a la propiedad de los sectores arrendatarios y aparceros, la producción y la construcción de viviendas rurales. También intentó terminar con los conflictos generados entre productores familiares y asalariados transitorios motivados por el uso obligatorio de mano de obra asalariada para ciertas actividades. El Plan proponía permitir a los productores familiares el uso de la fuerza de trabajo familiar y de sus propios medios de transporte (Lattuada, 1986; Olivera, 2015)

12 Quinto: Condiciones impuestas por el Banco Nación Argentina a las Sociedades Cooperativas para el otorgamiento de créditos: Se dá lectura a las condiciones que el Banco de La Nación Argentina en su Sucursal de Casilda nos ha pasado ante nuestra solicitud de crédito cuyas disposiciones son las siguientes. Primero) A permitir la inspección de sus libros de contabilidad y documentación respectiva cuando el Banco así lo requiera, con el objeto de verificar su organización y poder indicar normas que consulten con mayor eficacia el sistema contable a que debe ajustarse en sus relaciones con sus asociados. Segundo) A elevar a conocimiento del Banco su presupuesto de gastos fijos y a no realizar inversiones en gastos ajenos a las partidas sancionadas. Tercero) A no hacer inversiones en adquisición de inmuebles sin conocimiento del Banco, cuando éste sea acreedor por créditos a sola firma. Cuarto) A requerir a sus asociados, sin excepción alguna, la documentación de los créditos que les acuerde y a cuidar que en la admisión de los mismos a la Cooperativa no se incorporen personas con intereses encontrados para sus actividades y que por tanto le resten su integral adhesión, condición indispensable para el éxito y desarrollo del Régimen Societario Cooperativo. Quinto) A pasar al Banco un estado semestral demostrativo de la situación y marcha de sus actividades. Sexto) A ajustar todas sus operaciones a las proscripciones de la Ley número once mil trescientos ochenta y ocho. Séptimo) A no realizar operaciones de especulación de naturaleza alguna. Octavo) A ajustar su acción a los principios económicos constitucionales, tendiendo al logro de los objetivos del Segundo Plan Quinquenal de Gobierno, según consagra en su capítulo X.G. veintidós. Noveno) A adoptar la doctrina Nacional consagrada por el Artículo tercero de la Ley número catorce mil ciento ochenta y cuatro, que tiene como finalidad suprema alcanzar la Felicidad del Pueblo y la Bonanza de La Nación, mediante la Justicia Social, la Independencia Económica y la Soberanía Nacional. Luego de ser debidamente interpretadas, la Asamblea las dá por aprobada, ratificando así lo actuado por el Consejo de Administración en su reunión del día cinco de noviembre de mil novecientos cincuenta y tres" (Acta No 7 Asamblea Gral. Ordinaria, el remarcado no corresponde a la versión original)

13 Propietarios de la estancia en la que eran arrendatarios.

14 En noviembre de 1943, bajo el gobierno del Gral. Ramírez, se dictó el Decreto-Ley No 14.001 que promovió la rebaja de un $20 \%$ de los arrendamientos agrícolas respecto a lo vigente en 1940, la suspensión de los juicios de desalojos hasta el fin de la cosecha en 1945, prorrogándose hasta 1947 por el Decreto-Ley №18.290. Además, el Decreto Ley № 14.001 estableció la obligatoriedad de la firma de contratos escritos entre las partes frente a escribano o juez de paz y su posterior registro en la División de Arrendamientos y Aparcerías del Ministerio de Agricultura. En 1946, bajo la primera presidencia de Perón, se dictó la Ley No 12.842 que amplió el alcance de las mencionadas prórrogas a los tambos, los arrendamientos en tierras fiscales y contratos de pastoreo. En 1948, se sancionó la Ley No 13.246, "Estatuto orgánico sobre arrendamientos y aparcerías rurales", en la que se explicitaron los derechos y deberes de cada parte y se flexibilizaron las obligaciones de los arrendatarios. Además, se crearon las Cámaras paritarias de conciliación y arbitraje obligatorio (Blanco, 2007; Lázzaro, 2015)

15 Hermano mayor del entrevistado $N^{\circ} 17$, mencionado en reiteradas oportunidades a lo largo de la entrevista.

16 AFA es una cooperativa de primer grado con una organización interna particular: los CCP están dirigidos por Consejos Asesores y la cantidad de miembros la determina el Consejo de Administración según considere pertinente teniendo en cuenta el volumen operado y las secciones operativas de cada CCP. En las Asambleas Anuales se eligen los representantes para la Asamblea de Delegados, entre los que se selecciona a quienes formarán el Consejo de Administración y el Asesor de cada CCP, que son nombrados por el Consejo de Administración Central. Los Consejos Asesores locales funcionan de manera semejante a los Consejos de Administración de las cooperativas de primer grado, pero están subordinados al Consejo de Administración Central. Además, cada CCP cuenta con un Gerente Apoderado que es el responsable de las tareas ejecutivas, depende del Consejo Asesor local y es responsable frente al Consejo de Administración central y al Gerente General de AFA (Lattuada y Renold, 2004) 